\title{
Thermal-mechanical Properties of Epoxy-impregnated Bi-2212/Ag Composite
}

\author{
Pei Li, Yang Wang, Arno Godeke, Liyang Ye, Gene Flanagan, and Tengming Shen Member, IEEE
}

\begin{abstract}
Knowledge of the thermal-mechanical properties of epoxy/superconductor/insulation composite is important for designing, fabricating, and operating epoxy impregnated high field superconducting magnets near their ultimate potentials. We report measurements of the modulus of elasticity, Poisson's ratio, and the coefficient of thermal contraction of epoxy-impregnated composite made from the state-of-the-art powder-in-tube multifilamentary $\mathrm{Ag} / \mathrm{Bi}_{2} \mathrm{Sr}_{2} \mathrm{CaCu}_{2} \mathrm{O}_{x}$ round wire at room temperature and cryogenic temperatures. Stress-strain curves of samples made from single-strand and Rutherford cables were tested under both monotonic and cyclic compressive loads, with single strands insulated using a thin $\mathrm{TiO}_{2}$ insulation coating and the Rutherford cable insulated with a braided ceramic sleeve.
\end{abstract}

Index Terms-Bi-2212/Ag, mechanical property, strain, thermal contraction, composite material modeling.

\section{INTRODUCTION}

$\mathrm{W}$ ith critical current densities $\left(J_{\mathrm{c}}\right)$ exceeding 2500 $\mathrm{A} / \mathrm{mm}^{2}$ in $20-30 \mathrm{~T}$ at $4.2 \mathrm{~K}[1,2], \mathrm{Bi}-2212 / \mathrm{Ag}$ round wire has long been considered as a candidate for constructing solenoids capable of generating fields that exceed the $\sim 22 \mathrm{~T}$ limit of $\mathrm{Nb}_{3} \mathrm{Sn}$ and constructing 16-20 $\mathrm{T}$ dipoles for particle accelerators. A critical issue is, however, how to manage the high electromagnetic stresses in such high field magnets. The conductors within these magnets are subject to enormous pressures when the magnet is operating; at $20 \mathrm{~T}$, the magnetic pressure is $320 \mathrm{MPa}$, high enough to cause plastic deformation of copper. Stress management will be a crucial design

Manuscript received August 12, 2014. This work was supported in part by an FY12 early career award from the Office of High Energy Physics (OHEP), U.S. Department of Energy and amplified by a SBIR phase I award from DOE-OHEP (DE-SC0011267).

Pei Li is with the Magnet Systems Department, Fermi National Accelerator Laboratory, Batavia, IL 60510, USA (e-mail: peili@fnal.gov).

Yang Wang is a graduate student with the Illinois Institute of Technology, Chicago, IL, 60616, USA and he is also with the Fermi National Accelerator Laboratory (e-mail: ywang@fnal.gov).

Arno Godeke was with the Lawrence Berkeley National Laboratory, Berkeley, CA 94720. He is now with the National High Magnetic Field Laboratory, Tallahassee, FL 32310 USA (agodeke@lbl.gov)

Liyang Ye is a graduate student with North Carolina State University, Raleigh, NC, 27695 USA and he is also with the Fermi National Accelerator Laboratory. (e-mail: ye1024@fnal.gov).

Gene Flanagan is with the Muons Inc., Batavia, IL, 60510, USA (e-mail: flanagan@muonsinc.com).

Tengming Shen is with the Magnet Systems Department, Fermi National Accelerator Laboratory, Batavia, IL 60510 USA (e-mail: tshen@fnal.gov). consideration for high-field magnets based on $\mathrm{Bi}-2212$ conductors since $\mathrm{Bi}-2212$ is brittle after reaction and its current-carrying capability depends on strain. $I_{\mathrm{C}}$ of Ag-sheathed $\mathrm{Bi}-2212$ wires is virtually insensitive to tensile strain up to a sample dependent strain limit, beyond which the $I_{\mathrm{c}}$ decreases quickly and irreversibly. Applying compressive strain to Ag-sheathed BSCCO conductor causes a gradual and irreversible decrease of $I_{\mathrm{c}}$ [3]. For commercial Ag-0.2 wt\% $\mathrm{Mg} / \mathrm{Ag} / \mathrm{Bi}-2212$ (area ratio AgMg:Ag:Bi-2212 = 0.25:0.5:0.25) round wire, the working stress maximum is around $120 \mathrm{MPa}$ at $4.2 \mathrm{~K}$ whereas the irreversible tensile strain is between $0.3 \%$ and $0.45 \%$. In addition to the electromagnetic stresses during normal operations, both solenoids and dipoles are subject to complex mechanical motions and significant non-uniform temperature changes during quenching, both resulting in changes in conductor strain states that can't be ignored when magnets work near their mechanical limits. Moreover, construction of cosine-theta dipoles requires the coils to be pre-stressed to reduce conductor motion and thus minimize the probability of motion-initiated quenches.

To understand and predict the strain state in the superconductor and devise a support structure capable of minimizing the stresses in the coils from magnet assembly to excitation, Fermilab initiated a program to measure and compute displacements, stress, and strain of all the components during assembling, cooling-down, and excitation for magnets. Here we report measurements of the mechanical properties and thermal contraction for epoxy-impregnated Bi-2212-based composite materials fabricated using the same method as for full size magnet coils.

\section{SAMPLE DESCRIPTION}

The wire stack samples were prepared as follows: commercial powder-in-tube $\mathrm{Bi}-2212 / \mathrm{Ag}$ wire from Oxford Superconducting Technology $(0.8 \mathrm{~mm}$ diameter, 37x18 filament architecture with filament diameter of $\sim 20 \mu \mathrm{m}$ ) were insulated with a $n \mathrm{Gimat} \mathrm{TiO}_{2}$ coating [4] that consisted of a $\mathrm{TiO}_{2}$ basecoat $\sim 20 \mu \mathrm{m}$ thick and a polymer top-coat $\sim 3 \mu \mathrm{m}$ thick. The wires were hexagonally wound around a small Inconel 600 racetrack mandrel, heat-treated in 1 bar flowing oxygen using a standard heat-treatment procedure [5] of $\mathrm{Bi}-2212 / \mathrm{Ag}$ wires, and then impregnated with epoxy (CTD-101K). After reaction, no visible signs of leakage were found but we believe that the coil contains leakage spots because of silver creep driven by internal gases common in the 1 bar melt processing of long-length Bi-2212 wires [6]. The outer sheath of the wire was Ag- $0.2 \mathrm{wt} \% \mathrm{Mg}$, with area ratio of 
AgMg:Ag:Bi-2212 $=0.25: 0.5: 0.25$. The density of filament was approximately $75 \%$ of theoretical value. The coil was expected to carry $\sim 65-80 \%$ of short sample $I_{\mathrm{c}}$ (short samples carried $\sim 440 \mathrm{~A}$ in self-field and $190 \mathrm{~A}$ in $5 \mathrm{~T}$ at $4.2 \mathrm{~K}$ ). The straight sections of the wire stack were cut (with Inconel removed) and polished. A typical sample size was about 12 $\mathrm{mm} \times 12 \mathrm{~mm}$ x $18 \mathrm{~mm}$ (axial direction). A typical sample contained about $13-15$ by 13-15 strands. Fig. 1a shows a typical sample stack. The mechanical properties of these samples are necessary for any detailed design study of solenoids wound from Bi-2212 strands.

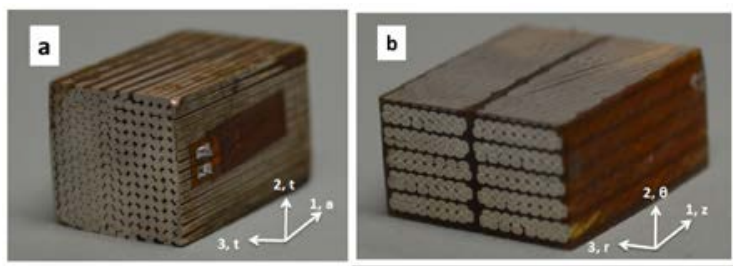

Figure 1. Samples with definition of loading directions: (a) strand sample ( $\mathrm{a}=$ axial, $\mathrm{t}=$ transverse); (b) cable sample ( $\mathrm{z}=$ axial, $\mathrm{r}=$ radial, $\boldsymbol{\theta}=$ azimuthal).

Table 1: Specifications of the strand composite sample

\begin{tabular}{cc}
\hline \hline Strand sample & \\
\hline Conductor & $\mathrm{Ag} / \mathrm{Bi}-2212$ \\
\hline External sheath & $\mathrm{Ag}-0.2 \mathrm{wt} \% \mathrm{Mg}$ \\
\hline AgMg:Ag:Bi2212 & $0.25: 0.50: 0.25$ \\
\hline Strand diameter & $0.8 \mathrm{~mm}$ \\
\hline Insulation & $\begin{array}{c}\text { nGimat } \mathrm{TiO}_{2} \\
\text { coating }\end{array}$ \\
\hline Insulation \\
thickness & $23 \mu \mathrm{m}$ \\
\hline Winding & Hexagonal \\
\hline $\begin{array}{c}\text { Sample size } \\
{\left[\mathrm{mm}^{3} \text { ] }\right.}\end{array}$ & $12 \times 12 \times 18$ \\
\hline \hline
\end{tabular}

Table 2: Specifications of the cable composite sample

\begin{tabular}{cc}
\hline \hline Cable sample & \\
\hline Conductor & $\begin{array}{c}\text { Same as strand } \\
\text { sample }\end{array}$ \\
\hline Cable width [mm] & 1.46 \\
\hline Cable \\
thickness[mm] & 7.80 \\
\hline Cable pitch length & $39 \mathrm{~mm}$ \\
\hline $\begin{array}{c}\text { No. of strands in a } \\
\text { cable }\end{array}$ & 17 \\
\hline Cable insulation & $\mathrm{Al}_{2} \mathrm{O}_{3}-\mathrm{SiO}_{2}$ \\
sleeve \\
\hline $\begin{array}{c}\text { Insulation } \\
\text { thickness }\end{array}$ & $150 \mu \mathrm{m}$ \\
\hline $\begin{array}{c}\text { Sample size } \\
{\left[\mathrm{mm}^{3} \text { ] }\right.}\end{array}$ & $8.5 \times 15.4 \mathrm{x}$ \\
20.6 \\
\hline \hline
\end{tabular}

The Rutherford cable samples (Fig 1b) were cut from a racetrack coil (HTS-SC04) fabricated at Lawrence Berkeley National Laboratory (LBNL) [7]. The Rutherford cables were made from a 17-strand Bi-2212 wire (the specification of single strand is similar to that described above) with a nominal cross-section of $1.46 \times 7.80 \mathrm{~mm}^{2}$. The pitch length of the cable was $39 \mathrm{~mm}$. Wires were not twisted before cabling. The cable was insulated with a braided Mullite fiber sleeve with a thickness $\sim 150 \mu \mathrm{m}$ (the sizing of the insulation was removed by baking the sleeve at $600{ }^{\circ} \mathrm{C}$ for 1 hour in a constant flow of $\mathrm{O}_{2}$ ). The racetrack coil contained two layers of Rutherford cables impregnated with CTD-101K epoxy. The coil was tested at LBNL and carried $1526 \mathrm{~A}$ at $4.2 \mathrm{~K}$. A typical mechanical sample size was $8.5 \mathrm{~mm}$ (azimuthal direction) by $15.4 \mathrm{~mm}$ (radial direction) by $20.56 \mathrm{~mm}$ (axial direction). Fig. 1b shows a typical cable composite sample. The mechanical properties of these samples are useful for designing and fabricating accelerator dipoles and quadruples made from $\mathrm{Bi}-2212$ Rutherford cable.

\section{Thermal Contraction MEASUREMENT}

\section{A. Measurement Method}

The thermal contraction of the $\mathrm{Bi}-2212$ samples was determined using a thin film gage technique. Strain gages (Micro-Measurements, WK-09 series) were mounted on the samples along principle orthogonal directions (defined in Fig. 1) using M-bond epoxy. Samples were then cooled down from room temperature to $77 \mathrm{~K}$ and $4.2 \mathrm{~K}$. Before and after cooling down, the resistances of the strain gauges were determined by the standard four-point method. The resistance change $\Delta R$ consists of: (i) resistance change of gage material with temperature; (ii) resistance change proportional to the thermal contraction difference between the gage grid alloy and the tested material. The thermal output, defined by $\varepsilon_{s}=\Delta R /\left(R_{0} \cdot F_{G}\right)\left(R_{0}\right.$ and $F_{\mathrm{G}}$ are the resistance of the strain gauge at room temperature and the gage factor), can be expressed as:

$$
\varepsilon_{s}=\frac{\Delta R}{R_{0} \cdot F_{G}}=\left[\frac{\beta_{G}}{F_{G}}+\left(\alpha_{s}-a_{G}\right)\right] \cdot \Delta T
$$

where $\beta_{\mathrm{G}}$ is the thermal coefficient of resistivity of gage grid material, $\left(\alpha_{\mathrm{s}}-\alpha_{\mathrm{G}}\right)$ is the thermal expansion coefficient difference between specimen and grid respectively, $\Delta T$ is the temperature change.

To obtain $\alpha_{\mathrm{s}}$, the same type of strain gage was mounted on a reference sample with known contraction coefficient $\alpha_{\mathrm{R}}$. The thermal output measured from the reference sample is:

$$
\varepsilon_{R}=\frac{\Delta R}{\left(R_{0} \cdot F_{G}\right)}=\left[\frac{\beta_{G}}{F_{G}}+\left(\alpha_{s}-\alpha_{R}\right)\right] \cdot \Delta T
$$

Subtracting (2) from (1), and rearranging,

$$
\alpha_{s}-\alpha_{R}=\frac{\left(\varepsilon_{s}-\varepsilon_{R}\right)}{\Delta T}
$$

It should be pointed out that thermal contraction coefficient is usually not a constant over a large $\Delta T$ and the $\alpha$ appearing in the above equations should be understood as $\varepsilon / \Delta T$. The reference samples used in this study were high purity quartz, of which thermal contraction was taken to be zero, and Al-6061. Several thermal cycles were performed to determine the repeatability 
and data scatter.

\section{B. Measurement Results and Comparison to Analytical Thermal Contraction}

The thermal contraction results are listed in table 3. For simplicity, $\alpha_{\text {quartz }}$ is taken to be zero. Data were averaged from three thermal cycles.

Table 3: Mean thermal contraction data for Bi2212 composite samples (specifications listed in table 1 and 2) from $293 \mathrm{~K}$ to $77 \mathrm{~K}$, and from $293 \mathrm{~K}$ to 4.2 K

\begin{tabular}{lll}
\hline \hline Temperature & $\begin{array}{l}\Delta \mathrm{L} / \mathrm{L} \\
(293 \mathrm{~K} \rightarrow 77 \mathrm{~K})\end{array}$ & $\begin{array}{l}\Delta \mathrm{L} / \mathrm{L} \\
(293 \mathrm{~K} \rightarrow 4.2 \mathrm{~K})\end{array}$ \\
\hline Strand - axial direction & $-0.316 \%$ & $-0.351 \%$ \\
\hline Strand - transverse direction & $-0.436 \%$ & $-0.493 \%$ \\
\hline Cable - axial direction & $-0.296 \%$ & $-0.326 \%$ \\
\hline Cable - radial direction & $-0.357 \%$ & $-0.397 \%$ \\
\hline Cable - azimuthal direction & $-0.489 \%$ & $-0.525 \%$ \\
\hline Al-6061 (measured) & $-0.387 \%$ & $-0.423 \%$ \\
\hline Al-6061 (theoretical) & $-0.389 \%$ & $-0.414 \%$ \\
\hline \hline
\end{tabular}

\section{ROOM TEMPERATURE AND 77 K MECHANICAL PROPERTY MEASUREMENT}

\section{A. Measurement Method}

Stress-strain curves for samples were tested under compression for principal orthogonal directions using a loader and a stainless steel sample fixture, as shown in Fig. 2. The sample fixture features guiding pins to minimize non-uniform loading, which is further minimized by carefully polishing samples to ensure the distance variation between each pair of parallel planes to be less than $\pm 0.8 \%$. For $77 \mathrm{~K}$ measurements, samples were placed in a cryostat immersed in liquid $\mathrm{N}_{2}$. The modulus of elasticity is calculated using Hooke's law.

To certify the validity and reproducibility of the measurement method, a reference Al-6061 sample was tested. The aluminum sample measured $12.7 \mathrm{~mm}$ x $12.7 \mathrm{~mm}$ x 25.4 $\mathrm{mm}$. The measured value of the Young's modulus is $72.2 \mathrm{GPa}$ (typically reported value is $69 \mathrm{GPa}$ ) whereas the measured Poisson's ratio at $293 \mathrm{~K}$ is 0.389 (comparing the typical reported value of about 0.35 ). The standard deviations of these measurements were lower than $6 \%$.

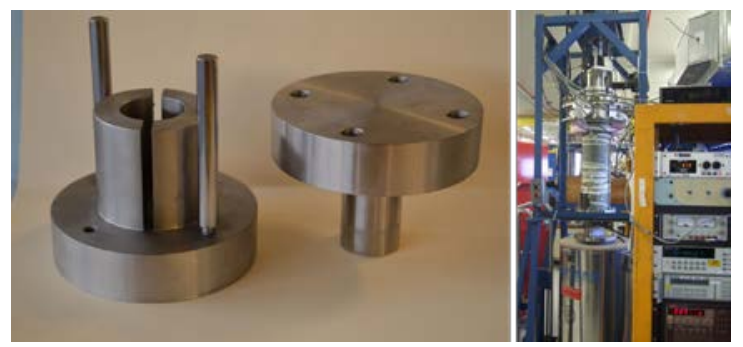

Fig. 2. Experimental setup used for the compression test. Left: The stainless steel compression test fixture that includes a bottom anvil (left) and a top piece (right). Right: the hydraulic loader with electronics and dewar.

\section{B. Modulus measurement of strand samples}

Table 4 lists the measured Young's modulus of the strand composite sample along both axial and transverse directions at $293 \mathrm{~K}$ and $77 \mathrm{~K}$. Table 4 also lists the room temperature, $77 \mathrm{~K}$ and $4 \mathrm{~K}$ elastic modulus for the strand composite sample calculated using a lamina modeling of fiber-embedded composite materials [8] by treating strands as fibers and epoxy as matrix. In this calculation, a Bi-2212 filling factor of $25 \%$ was used. A strand-packing factor of 0.785 was used for the strand sample and the epoxy was assumed to completely fill the gaps between strands. The calculation results agreed reasonably well with the experimental results.

\begin{tabular}{lll} 
Table 4: Elastic Modulus for Bi-2212 composite (strand sample) \\
\hline \hline Temperature & $\begin{array}{l}\text { Axial } \\
(\mathrm{GPa})\end{array}$ & $\begin{array}{l}\text { Transverse } \\
(\mathrm{GPa})\end{array}$ \\
\hline $293 \mathrm{~K}$ measured) & 48.6 & 25.8 \\
\hline $77 \mathrm{~K}$ (measured) & 54.19 & 27.21 \\
\hline $293 \mathrm{~K}$ (calculated) & 51.64 & 24.01 \\
\hline $77 \mathrm{~K}$ (calculated) & 56.46 & 28.62 \\
\hline $4.2 \mathrm{~K}$ (calculated) & 57.93 & 31.38 \\
\hline \hline
\end{tabular}

The Young's modulus values listed in table 4 were measured with applied stresses no greater than $20 \mathrm{MPa}$, below which the stress - strain curves of the strand sample remain linear. Stress-strain curves of $\mathrm{Bi}-2212$ strands were reported to become nonlinear for stress greater than $\sim 40 \mathrm{MPa}$ in the axial direction. Figure 3 shows the stress-strain curve of the strand sample loaded axially (cyclic loading, $77 \mathrm{~K}$ ) up to $105 \mathrm{MPa}$. Both nonlinear strain-stress behavior and strain hardening effects were observed.

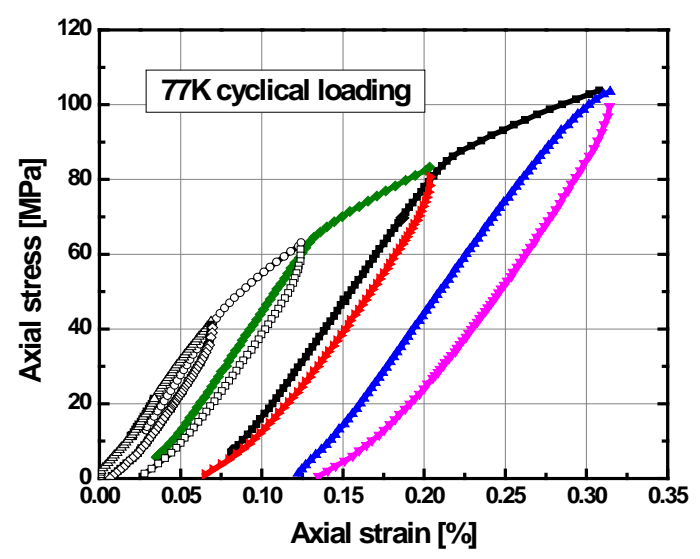

Fig. 3. Stress strain curves of the strand sample along the axial direction under cyclic loading with stress up to $105 \mathrm{MPa}$ at $77 \mathrm{~K}$

\section{Poisson's ratio measurement results of strand samples}

The Poisson's ratio measurement results are shown in Fig. 4 for which the loading direction was axial and the test occurred at $293 \mathrm{~K}$. Table 5 summarizes the Poisson's ratios at $293 \mathrm{~K}$ and $77 \mathrm{~K}$. For the strand samples, the Young's modulus and Poisson's ratio satisfies $\mathrm{E}_{1} / v_{12}=\mathrm{E}_{2} / v_{21}$, a typical behavior of orthotropic materials.

Table 5: Poisson's ratios for Bi-2212 composite (strand sample)

\begin{tabular}{lll}
\hline \hline Temperature & $v_{12}$ & $v_{21}$ \\
\hline $293 \mathrm{~K}$ (measured) & 0.35 & 0.16 \\
\hline 77 K (measured) & 0.36 & 0.14 \\
\hline \hline
\end{tabular}




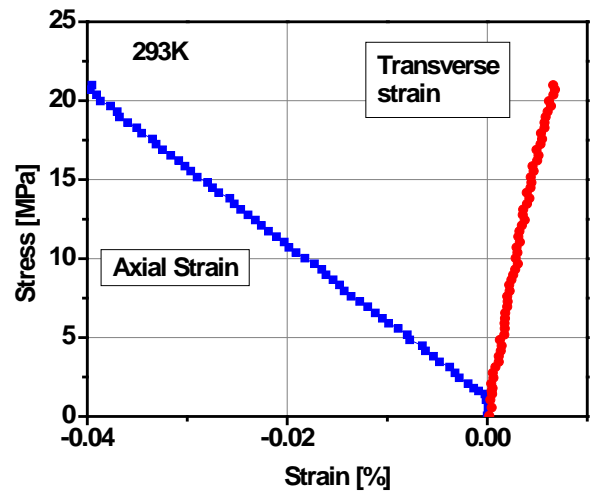

Fig. 4. Stress - strain measurement of the strand composite sample at room temperature. The loading was in axial direction and the strain was measured along axial and transverse directions.

\section{Modulus measurement of cable samples}

Table 6 lists the Young's modulus values of the cable composite sample along three orthogonal directions. The Young's modulus values listed in table 6 were measured with applied stresses up to $20 \mathrm{MPa}$.

Table 6: Elastic modulus for the Bi-2212 cable composite sample

\begin{tabular}{llll}
\hline \hline Temperature & $\begin{array}{l}\text { Axial } \\
\text { (GPa) }\end{array}$ & $\begin{array}{l}\text { Azimuthal } \\
\text { (GPa) }\end{array}$ & $\begin{array}{l}\text { Radial } \\
\text { (GPa) }\end{array}$ \\
\hline 293 K (measured) & 38.58 & 18.2 & 12.68 \\
\hline 77 K (measured) & 40.21 & 20.5 & 14.0 \\
\hline \hline
\end{tabular}

\section{E. Poisson's ratio measurement results of cable samples}

The Poisson's ratio measurements are shown in Fig. 5 for which the loading direction is azimuthal and the test occurred at $293 \mathrm{~K}$. Table 7 summarizes the Poisson's ratios at $293 \mathrm{~K}$ and 77 K.

Table 7: Poisson's ratios for Bi-2212 composite (strand sample)

\begin{tabular}{lllll}
\hline \hline Temperature & $v_{31}$ & $v_{13}$ & $v_{12}$ & $v_{21}$ \\
\hline 293 K (measured) & 0.31 & 0.11 & 0.13 & 0.40 \\
\hline 77 K (measured) & 0.31 & 0.12 & 0.12 & 0.37 \\
\hline \hline
\end{tabular}

Note that the cable results reported above were measured with gages mounted on a layer of epoxy. If the cable samples were further polished so that the gages were mounted on the exposed strands, complicated strain-stress curves and Poisson's ratio results were observed. Poisson's ratio exceeded 0.5 or even 1 in such situation. This is probably because of the structure of cables; the strands are twisted and transposed so the loading directions were not strictly along principal orthogonal directions. Loading off axis may result in complicated local stress on the strand. Similar behavior has been reported in study of fiber-reinforced materials loaded along off-axis directions [9]. On the other hand, results measured by gages mounted on epoxy may be considered as an average behavior.

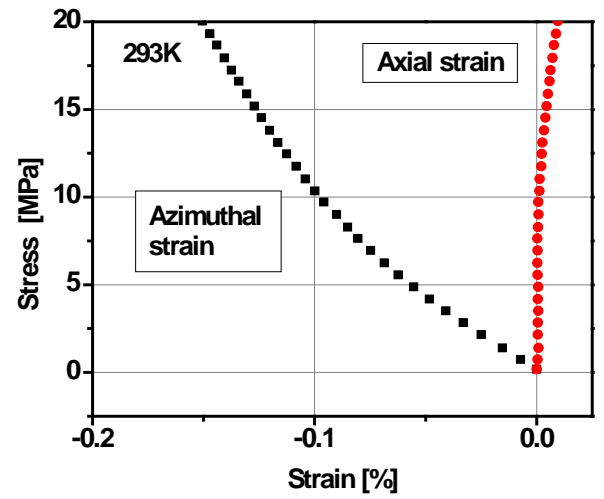

Fig. 5. Stress - strain measurement of the cable composite sample at room temperature. The loading was in azimuthal direction and the strains were measured along azimuthal and axial directions.

\section{CONCLUSION}

The stress-strain curves and the thermal contraction coefficients of epoxy/Ag-Bi2212 composites were experimentally established. The measurements are compared to values estimated using a rule of mixture calculation. The calculation is reasonably consistent with the experimental data. This data may be used for designing and operating high field magnets based on $\mathrm{Bi}-2212 / \mathrm{Ag}$ wires.

\section{ACKNOWLEDGEMENT}

We thank Steve Krave and Tomas Wokas for their assistance during experiments.

\section{REFERENCES}

[1] D. Larbalestier, J. Jiang, U. Trociewitz, F. Kametani, C. Scheuerlein, M. Dalban-Canassy, et al., "Isotropic round-wire multifilament cuprate superconductor for generation of magnetic fields above 30 T," Nat. Mater., vol. 13, p. 375, 2014.

[2] H. Miao, K. R. Marken, M. Meinesz, B. Czabaj, and S. Hong, "Development of round multifilament $\mathrm{Bi}-2212 / \mathrm{Ag}$ wires for high field magnet applications," IEEE Trans. Appl. Supercond., vol. 15, p. 2554-2557, 2005.

[3] N. Cheggour, X. Lu, T. Holesinger, T. Stauffer, J. Jiang, and L. Goodrich, "Reversible effect of strain on transport critical current in $\mathrm{Bi}_{2} \mathrm{Sr}_{2} \mathrm{CaCu}_{2} \mathrm{O}_{8+\mathrm{x}}$ superconducting wires: a modified descriptive strain model," Supercond. Sci. Technol., vol. 25, p. 015001, 2012.

[4] P. Chen, U. P. Trociewitz, M. Dalban-Canassy, J. Jiang, E. E. Hellstrom, and D. C. Larbalestier, "Performance of titanium oxide?polymer insulation in superconducting coils made of $\mathrm{Bi}-2212 / \mathrm{Ag}$-alloy round wire," Supercond. Sci. Technol., vol. 26, p. 075009, 2013.

[5] T. Shen, J. Jiang, F. Kametani, U. P. Trociewitz, D. C. Larbalestier, and E. E. Hellstrom, "Heat treatment control of $\mathrm{Ag}-\mathrm{Bi}_{2} \mathrm{Sr}_{2} \mathrm{CaCu}_{2} \mathrm{O}_{\mathrm{x}}$ multifilamentary round wire: investigation of time in the melt," Supercond. Sci. Technol., vol. 24, p. 115009, 2011.

[6] T. Shen, A. Ghosh, L. Cooley, and J. Jiang, "Role of internal gases and creep of Ag in controlling the critical current density of Ag-sheathed $\mathrm{Bi}_{2} \mathrm{Sr}_{2} \mathrm{CaCu}_{2} \mathrm{O}_{x}$ wires," J. Appl. Phys., vol. 113, p. 213901, 2013.

[7] A. Godeke, P. Acosta, D. Cheng, D. R. Dietderich, M. G. T. Mentink, S. O. Prestemon, et al., "Wind-and-react Bi-2212 coil development for accelerator magnets," Supercond. Sci. Technol., vol. 23, p. 034022, 2010.

[8] R. F. Gibson, Principles of composite material mechanics: CRC Press, 2011.

[9] L. Peel, "Exploration of high and negative Poisson's ratio elastomer matrix laminates," Phys. Status Solidi B, vol. 244, p. 988-1003, 2007. 